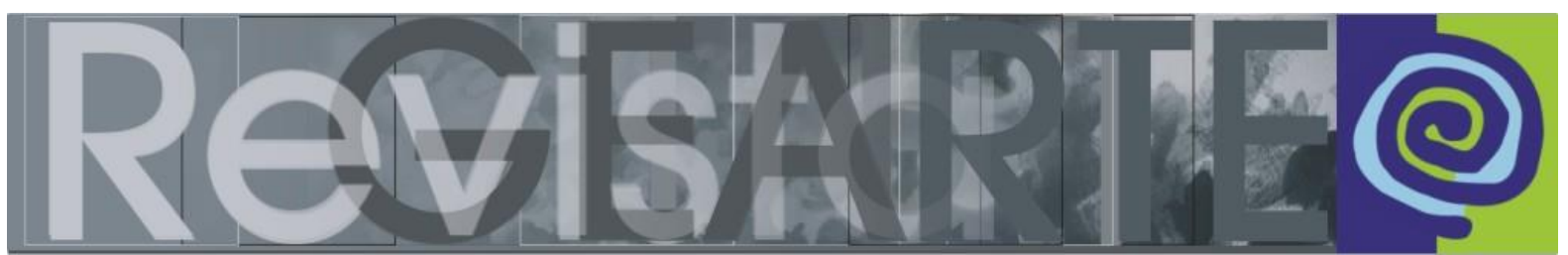

ISSN 2357-9854 | e-ISSN 2596-3198 (online)

\title{
OBEDIÊNCIA: \\ processos de ensinar, aprender e artistar
}

\author{
Luciana Borre \\ (Universidade Federal de Pernambuco - UFPE, Recife/PE, Brasil)
}

\begin{abstract}
RESUMO - OBEDIÊNCIA: processos de ensinar, aprender e artistar - Obediência é uma série de vivências poéticas e narrativas inscritas nas práticas contemporâneas em arte têxtil. Parto de um relato pessoal e de um artefato afetivo (vestidinho branco) para ressignificar minha trajetória como professora artista, perguntando: como narrativas autobiográficas ecoam em processos de ensinar, aprender e artistar? É parte da pesquisa a/r/tográfica "Narrativas Têxteis e Formação do Docente Artista" em desenvolvimento no Programa Associado de Pós-Graduação em Artes Visuais UFPE/UFPB e nos cursos de Graduação em Artes Visuais - Licenciatura e Bacharelado - da Universidade Federal de Pernambuco.
\end{abstract}

\section{PALAVRAS-CHAVE:}

Pesquisa Narrativa A/r/tográfica. Cultura Visual. Formação Docente. Arte Têxtil.

\begin{abstract}
OBEDIENCE: processes of teaching and learning - "Obediência" is a series of poetic and narrative experiences inscribed in contemporary textile processes. I start from a personal account and an affective artifact (little white dress) to reframe my trajectory as an artist teacher, asking: how do my autobiographical narratives reflects in the processes of teaching and learning? It is part of the $\mathrm{a} / \mathrm{r} / \mathrm{tographic}$ research "Textile Narratives and Artist Teacher Training" under development in the Associated Post-Graduate Program in Visual Arts UFPE/UFPB and in the Undergraduate courses in Visual Arts at the Universidade Federal de Pernambuco.
\end{abstract}

KEYWORDS:

Narrative A/r/tographic Research. Visual Culture. Teacher Education. Textile Art.

RESUMEN - OBEDIENCIA: procesos de enseñanza, aprendizaje y artistaje - "Obediência" es una serie de experiencias poéticas y narrativas ubicadas en procesos textiles contemporáneos. Partí de un relato personal y un artefacto afectivo (pequeño vestido blanco) para replantear mi trayectoria como artista y maestra, preguntando: ¿cómo resuenan mis narrativas autobiográficas en los procesos de enseñanza, aprendizaje y de arte? Es parte de la investigación a/r/tográfica "Narrativas Textiles y Formación del Profesorado" en desarrollo en el Programa de Posgrado Asociado en Artes Visuales UFPE/UFPB y en los cursos de pregrado en Artes Visuales en la Universidade Federal de Pernambuco.

PALABRAS CLAVE:

Investigación Narrativa A/r/tográfica. Cultura Visual. Formación del profesorado. Arte Textil. 

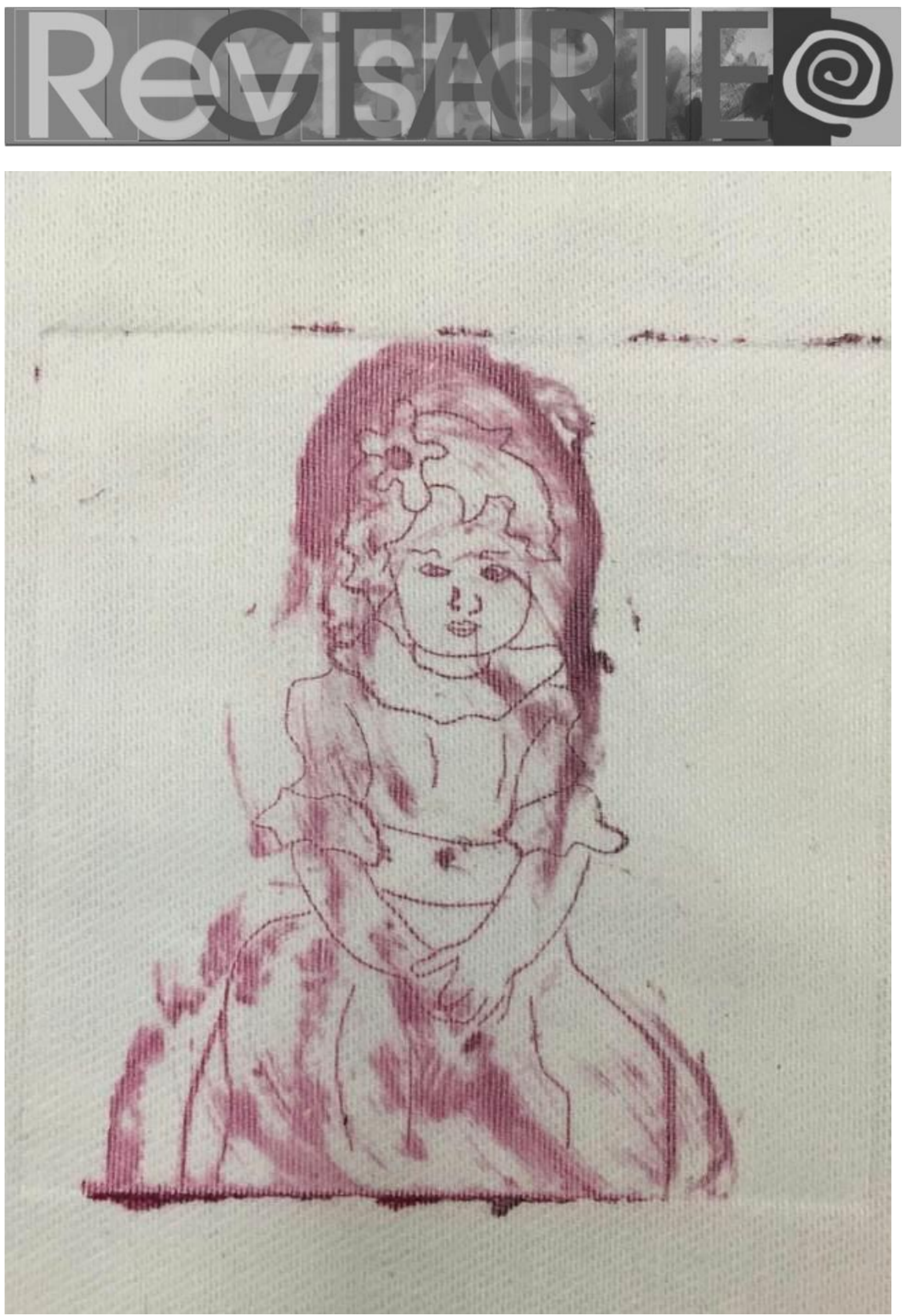

Calcogravura com Impressão em tecido, 2019.

BORRE, Luciana. OBEDIÊNCIA: processos de ensinar, aprender e artistar. Revista GEARTE, Porto Alegre, v. 8, n. 1, p. 181-196, jan./abr. 2021.

Disponível em: http://seer.ufrgs.br/gearte 

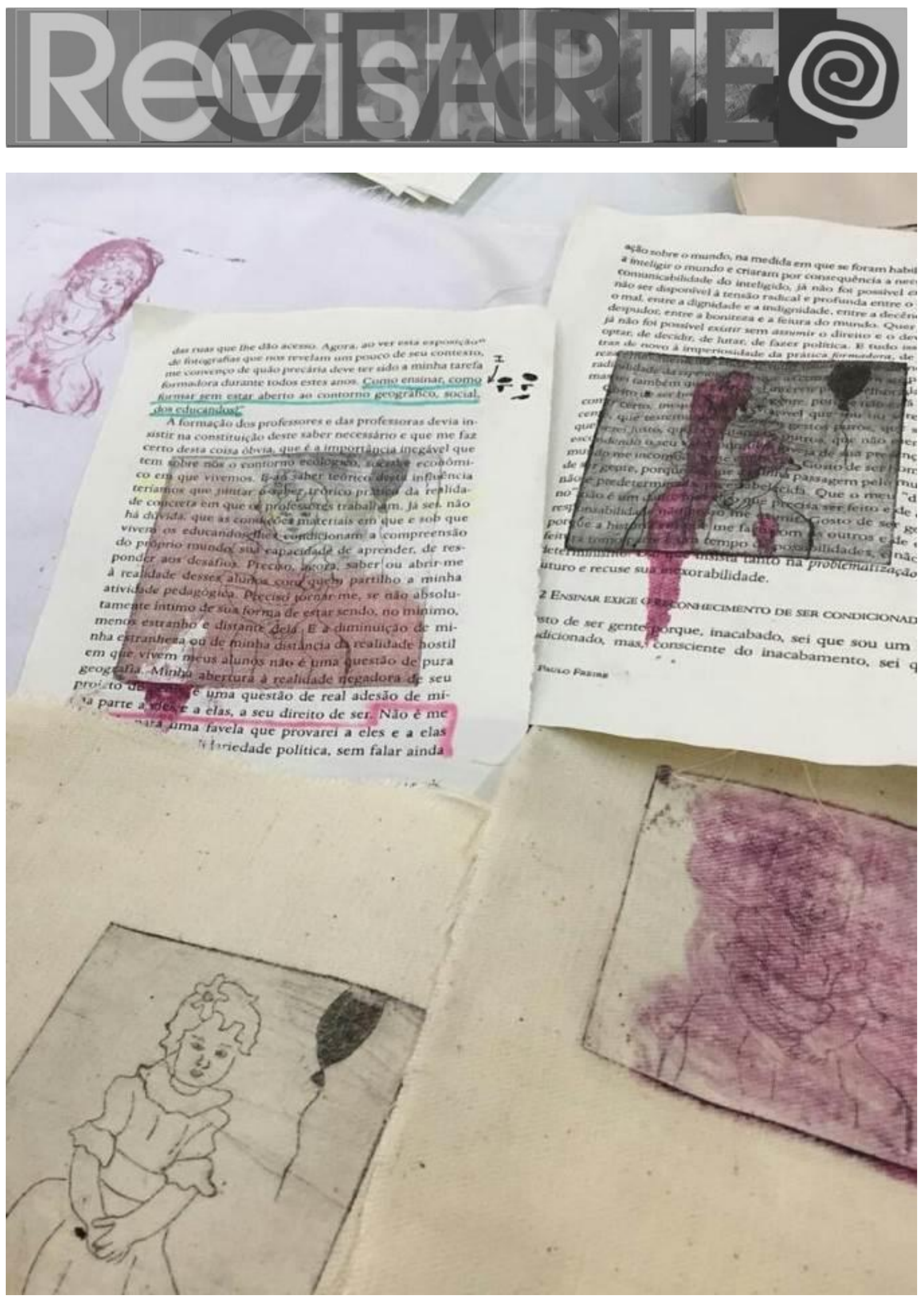

Calcogravura com impressões em materiais diversos, 2019. 


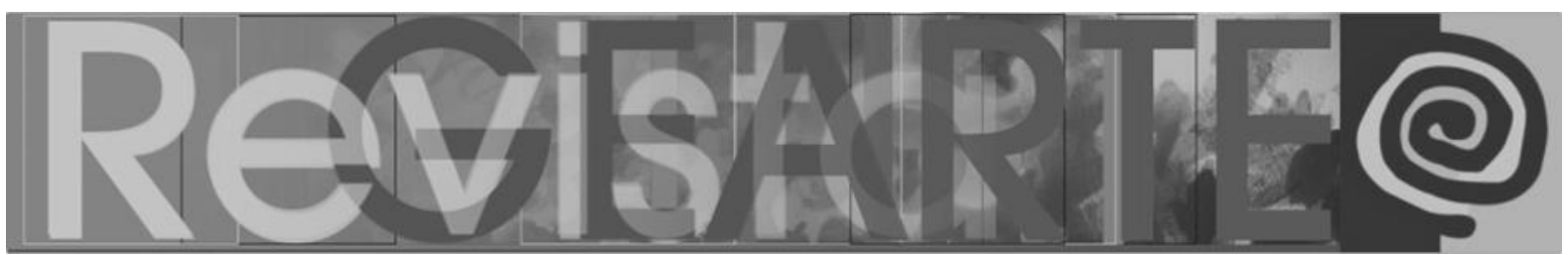

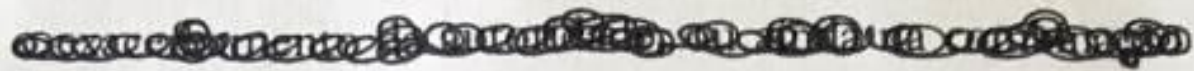
aras

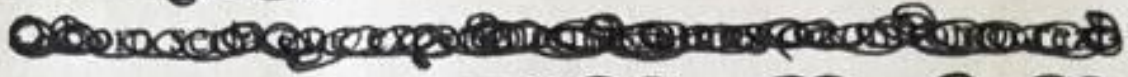

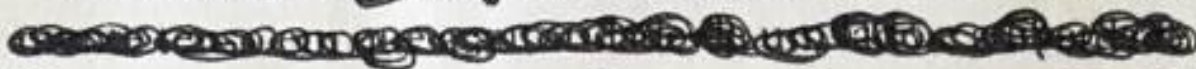

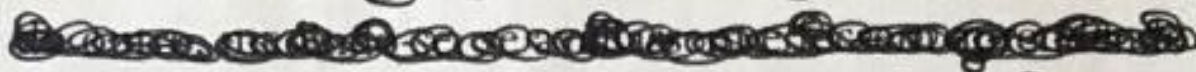

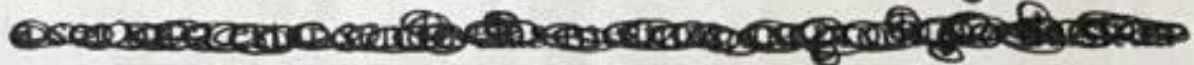

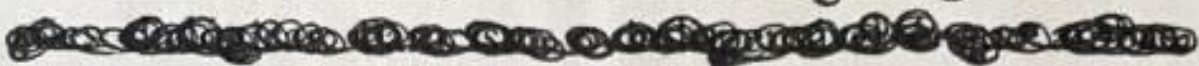

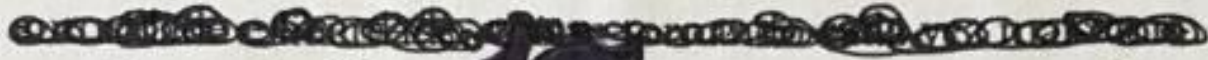

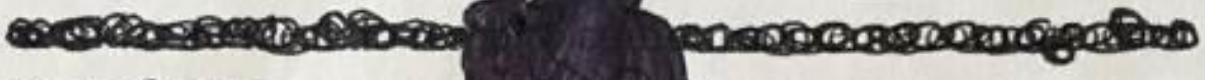

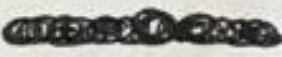

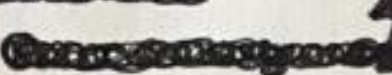
moremes

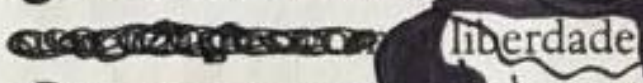

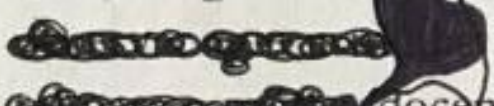
experiêncla

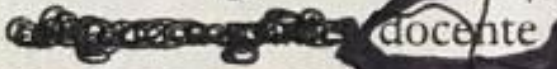
armenes 2000 8moras? ene perenty लmentiry ซrencer

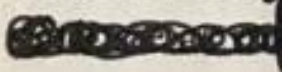

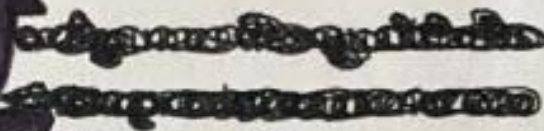

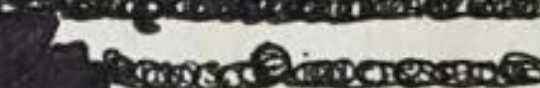

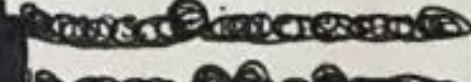
लmros a yes megrems

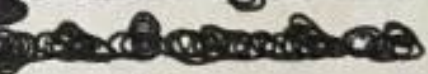

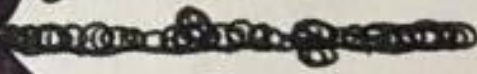

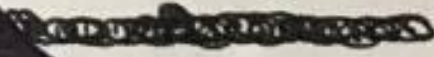
Arosionos memangafyes motichanitic

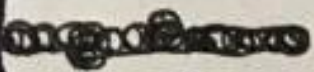

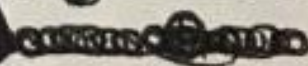
A frapcos as

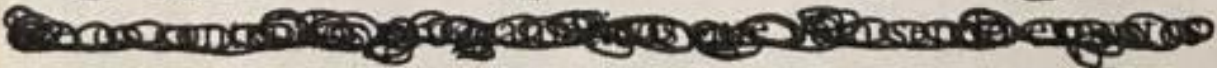

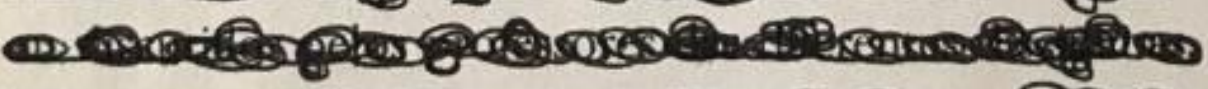

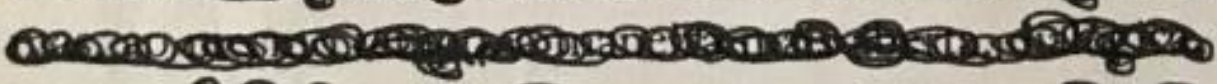

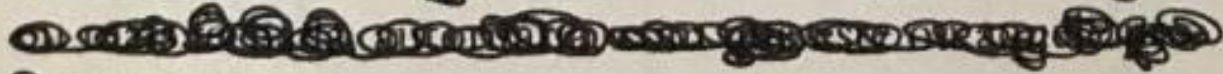

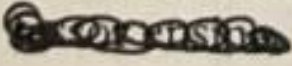

Intervenção no livro "Pedagogia da Autonomia", 2019. 

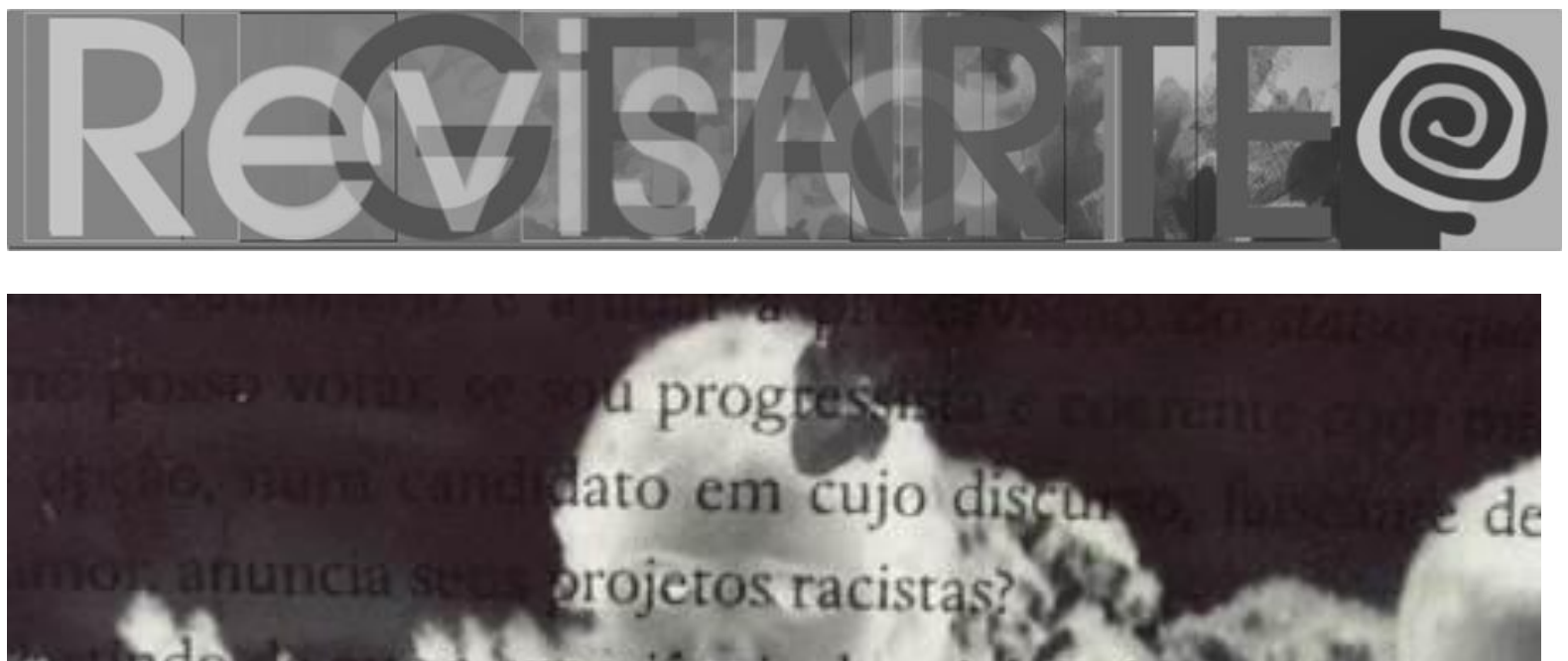

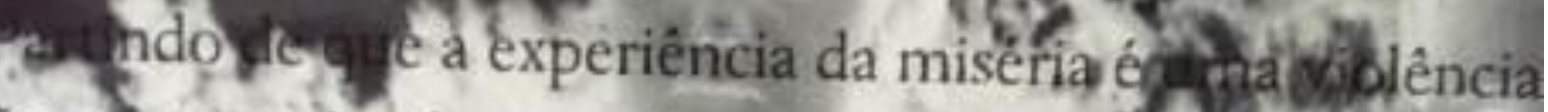
io a expressăo da preguica popular ou ffruto da mestiça o ou da verotade plinnitiva de Deus, violépcia contía que emos lutar, tembo, c

a vez mais competer

ue o saber de que fale

que ne empurra esp ge me in tentinaro er perde ficácia. sara a eficácia nesessári uanto nele fund is em cujo cay tica se base cisos sobre ay ologia, sobre rita? Por outrg npo, no da alf jetos coopera 1 ir confiecen iduzem sua própria sobfevivêncta precisoter eisentar saber especiba curi tonguieta e minha pnhecimentos linguagem e feitura eda rta em que ômica em da saúde, Como educador preciso in "lendo" cada vez melhor a leia do mundo que os grumos nonthares fom nuem trahalhn Intervenção no livro "Pedagogia da Autonomia", 2019. 

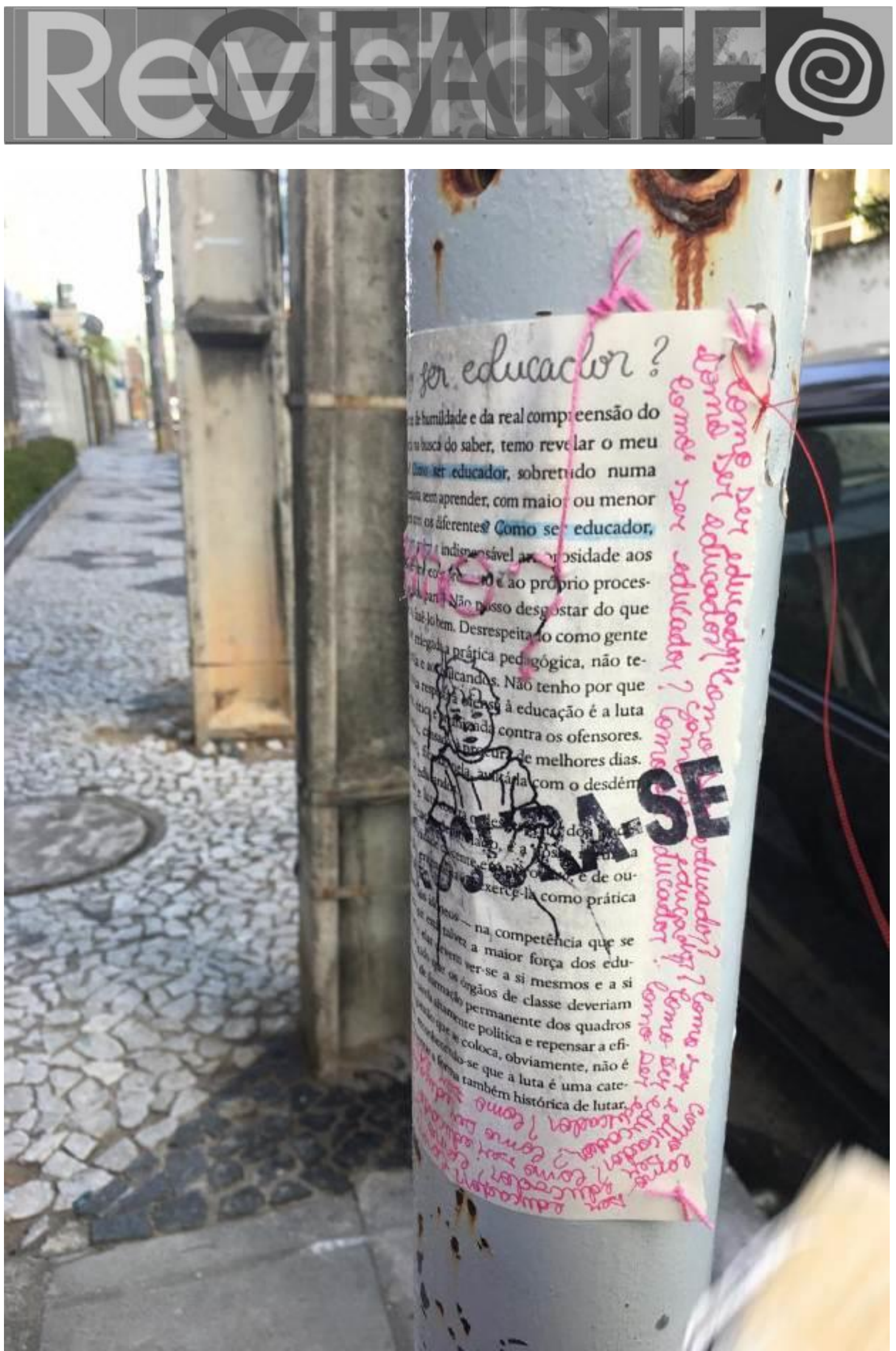

Carimbo e lambe-lambe, 2019. 

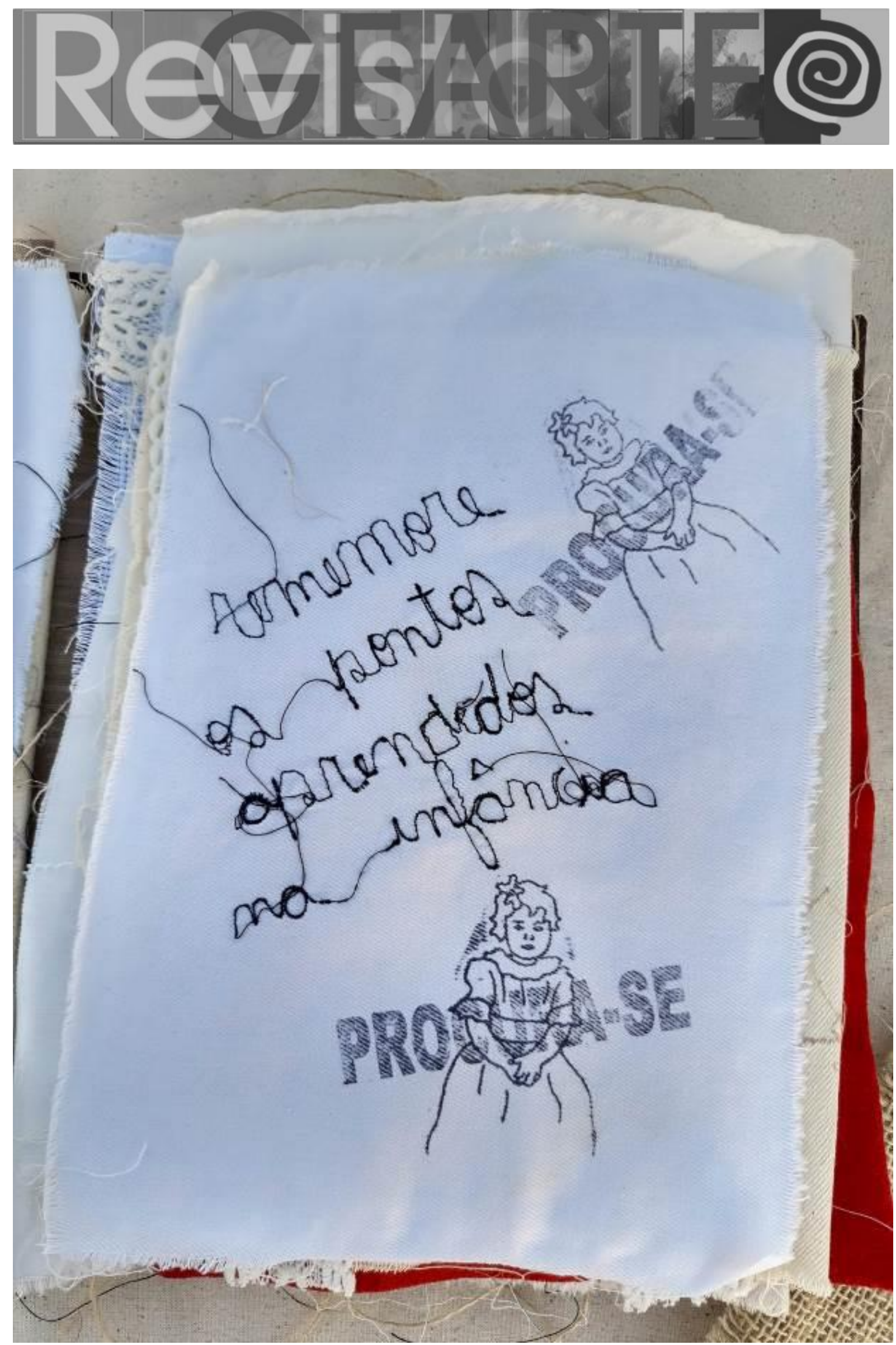

Livro Têxtil e Carimbo, 2020.

BORRE, Luciana. OBEDIÊNCIA: processos de ensinar, aprender e artistar Revista GEARTE, Porto Alegre, v. 8, n. 1, p. 181-196, jan./abr. 2021.

Disponível em: http://seer.ufrgs.br/gearte 

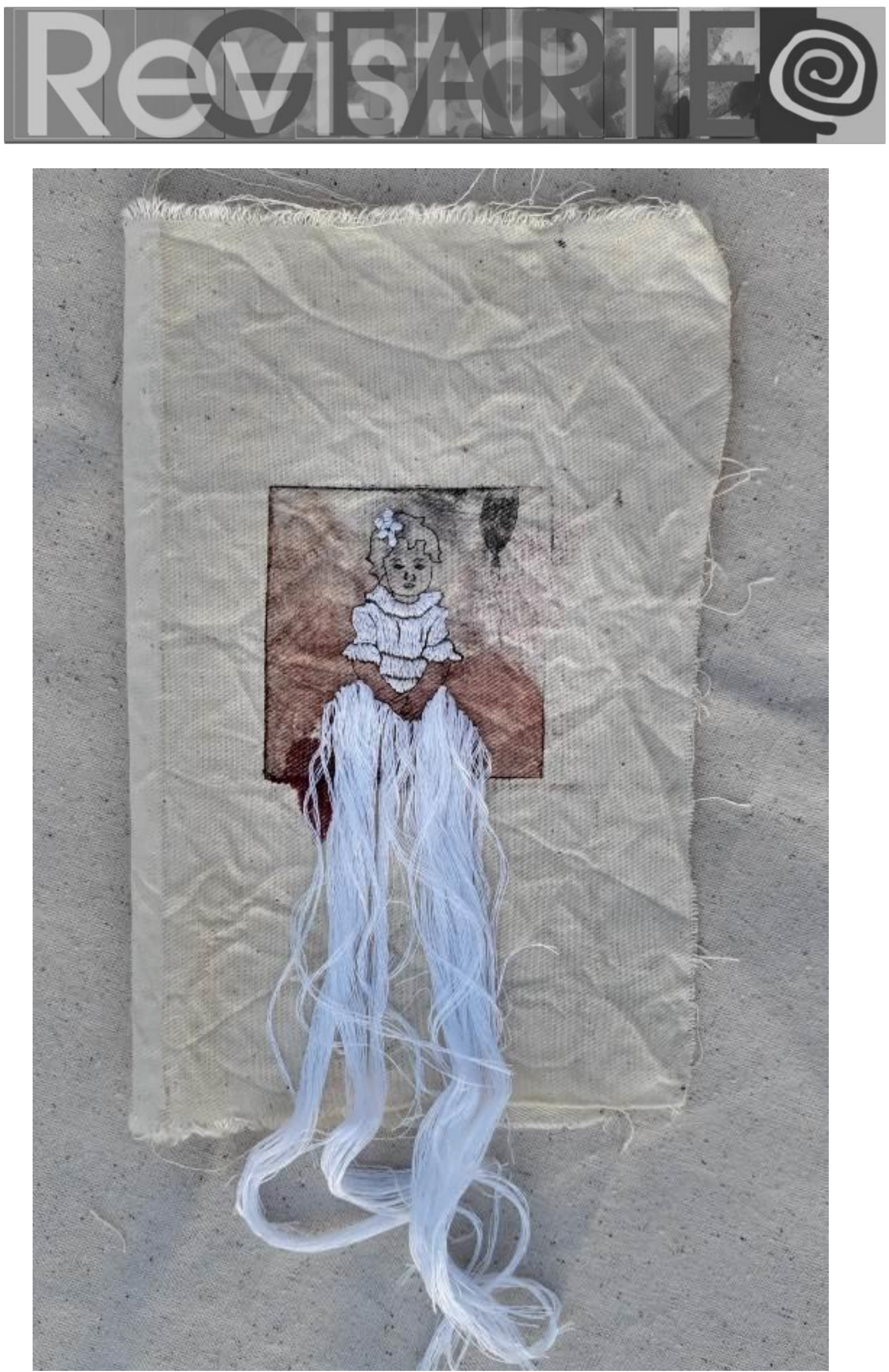

Bordado, 2020.

BORRE, Luciana. OBEDIÊNCIA: processos de ensinar, aprender e artistar. Revista GEARTE, Porto Alegre, v. 8, n. 1, p. 181-196, jan./abr. 2021.

Disponível em: http://seer.ufrgs.br/gearte 

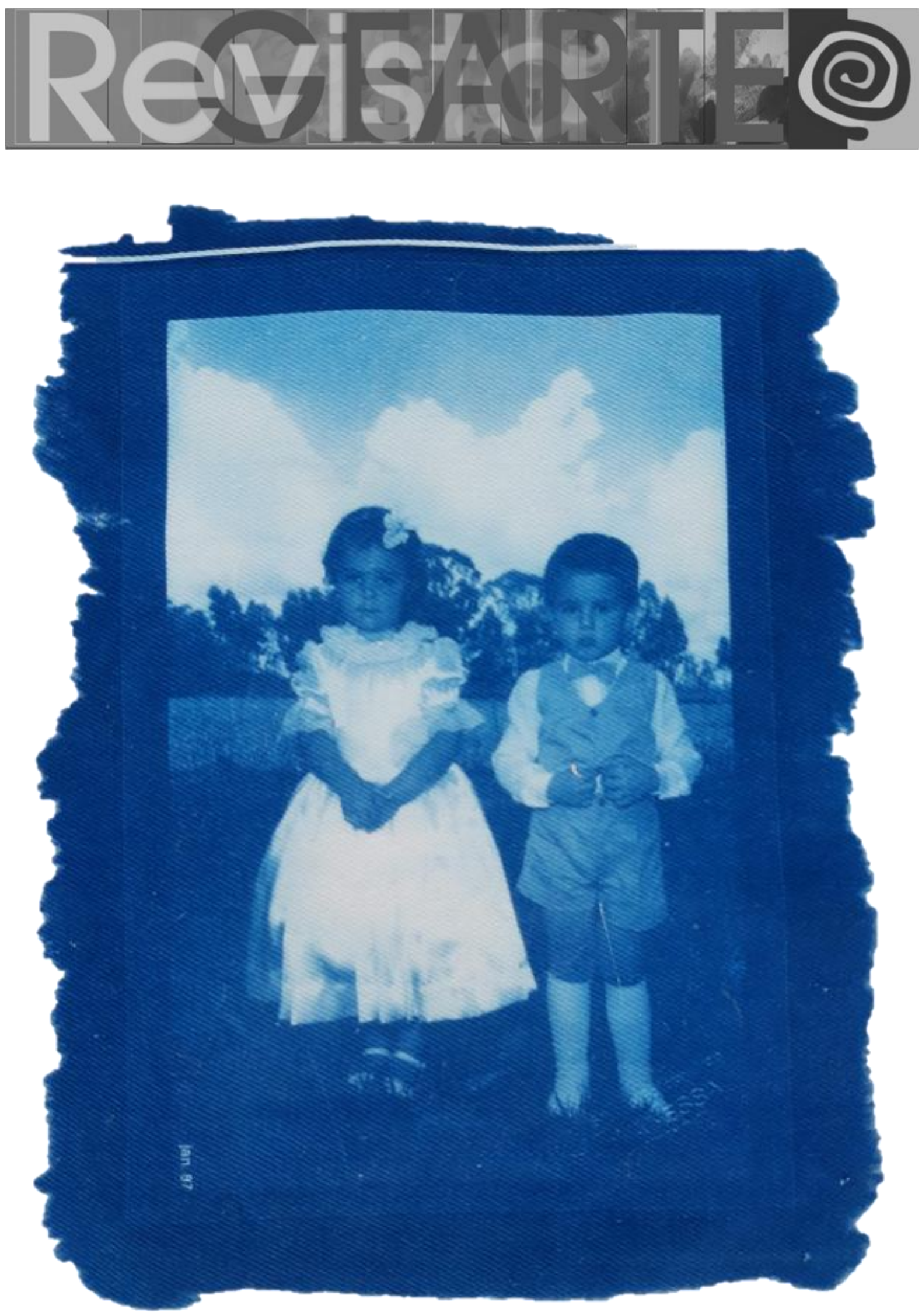

Cianotipia, 2019.

BORRE, Luciana. OBEDIÊNCIA: processos de ensinar, aprender e artistar. Revista GEARTE, Porto Alegre, v. 8, n. 1, p. 181-196, jan./abr. 2021.

Disponível em: http://seer.ufrgs.br/gearte 

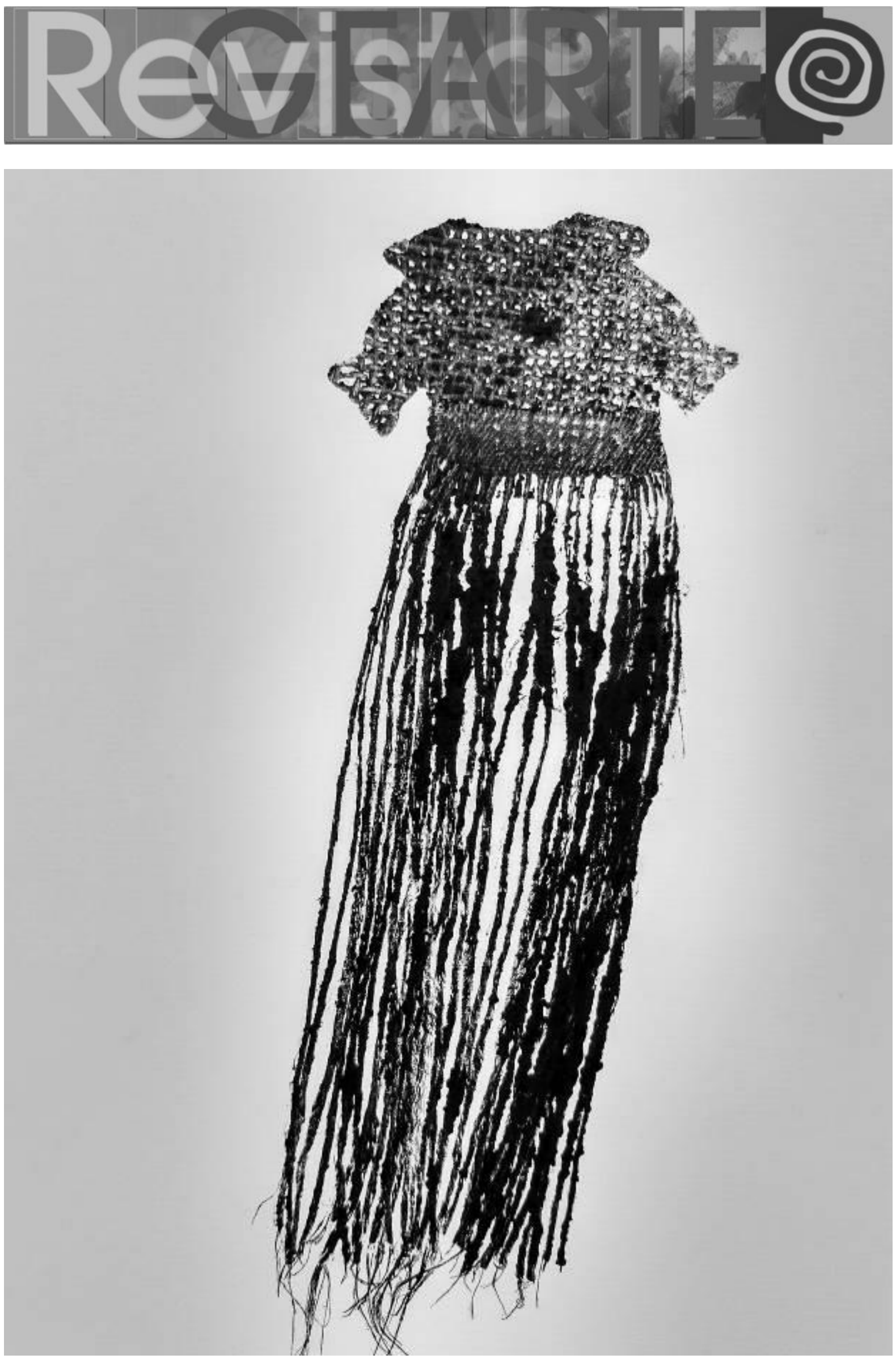

Collagraph com impressão em papel, 2020.

BORRE, Luciana. OBEDIÊNCIA: processos de ensinar, aprender e artistar. Revista GEARTE, Porto Alegre, v. 8, n. 1, p. 181-196, jan./abr. 2021. 

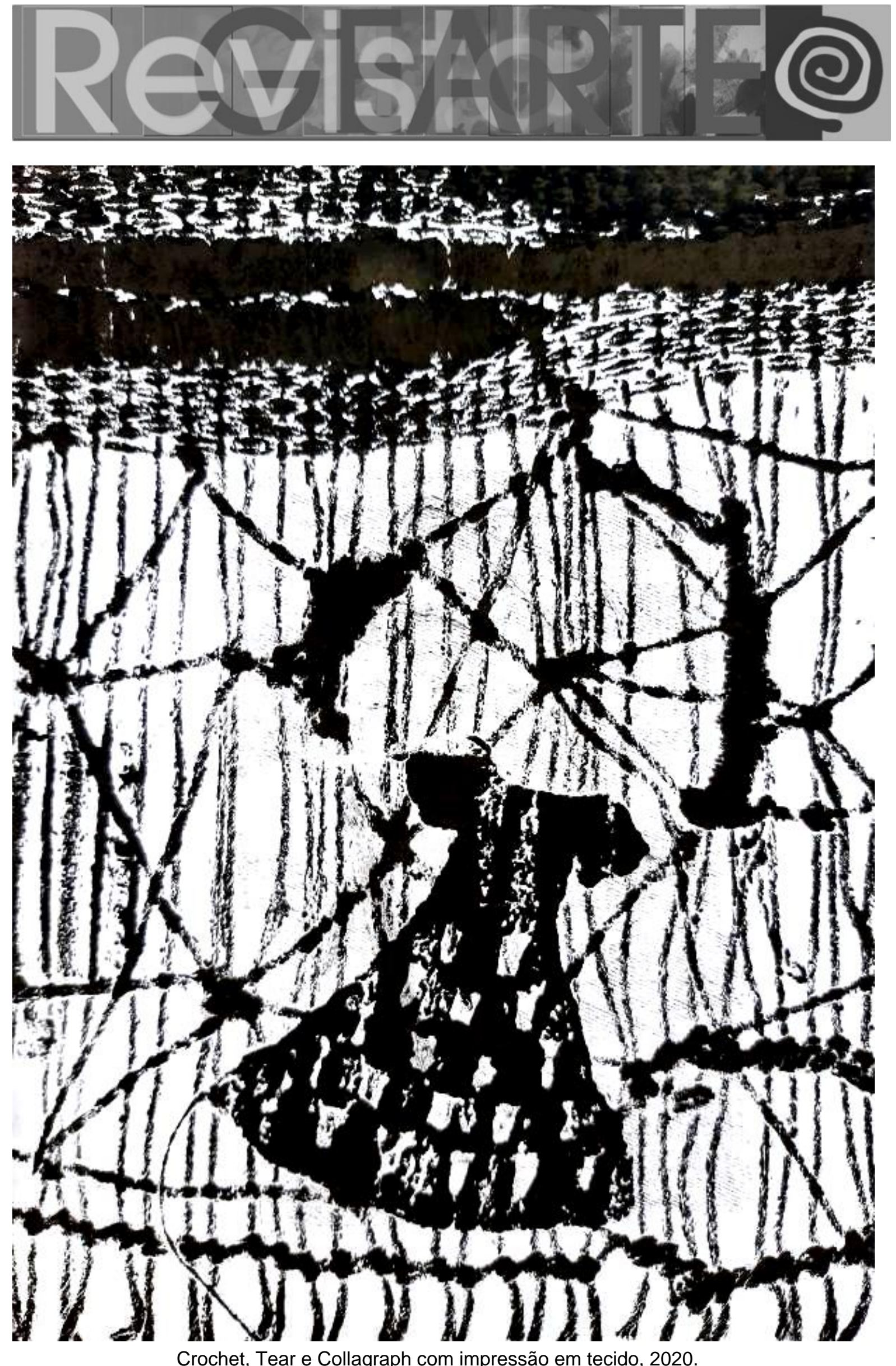

BORRE, Luciana. OBEDIÊNCIA: processos de ensinar, aprender e artistar.

19

Revista GEARTE, Porto Alegre, v. 8, n. 1, p. 181-196, jan./abr. 2021

Disponível em: http://seer.ufrgs.br/gearte 


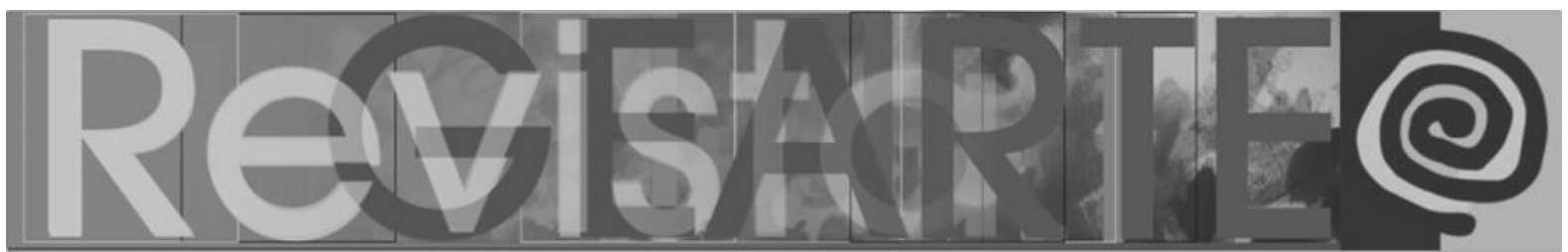

Anter de adormecer pede ajuda parta olhar a verdade em mum. tentava superar a triateza da rejecsáo

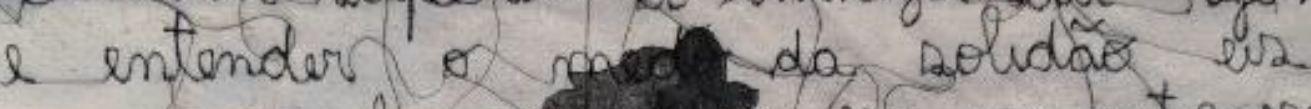

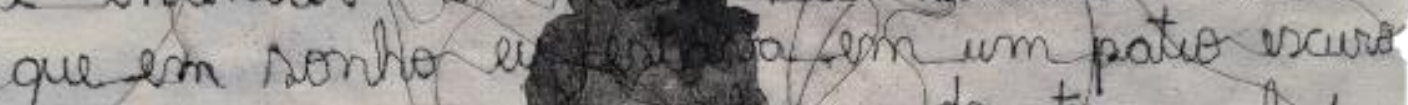
de uma cosa quel wee stacando tatanquilidar

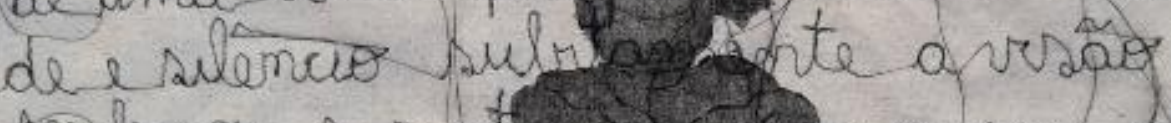

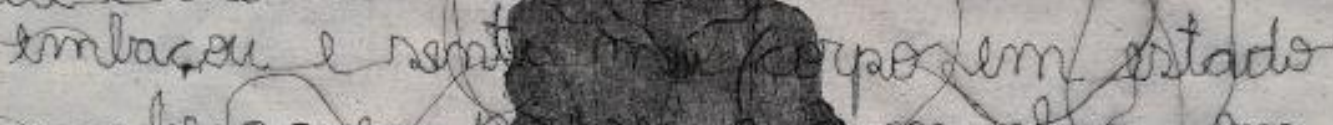
embriaguez he ssie o smixhor forn

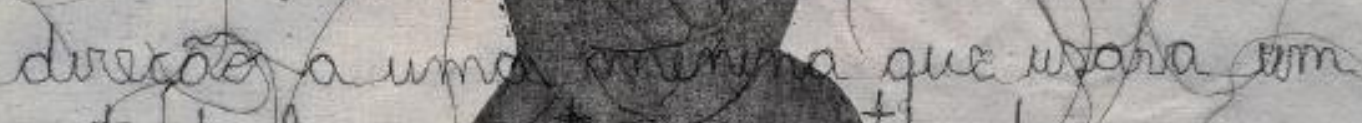
vestedinhore autasro ce ta de que se tratara de mim thuscarafanroxamacasos

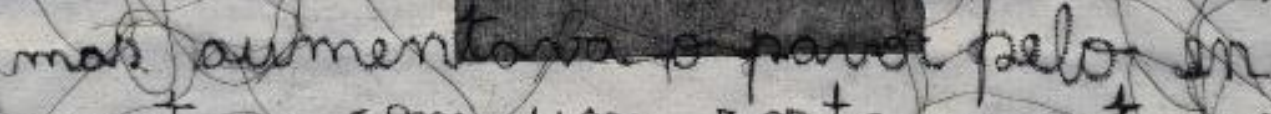
contro com sum rosto monstruioso perde ayuda movamente le sentindor. me resguardada me aproxumee me reconnece mas o rosto tinha as ferceser de uma de inkancia emocienada pede desculpas virantemente. supaty linda linda linda.

Collagraph com impressão em tecido e bordado livre à máquina, 2020. 

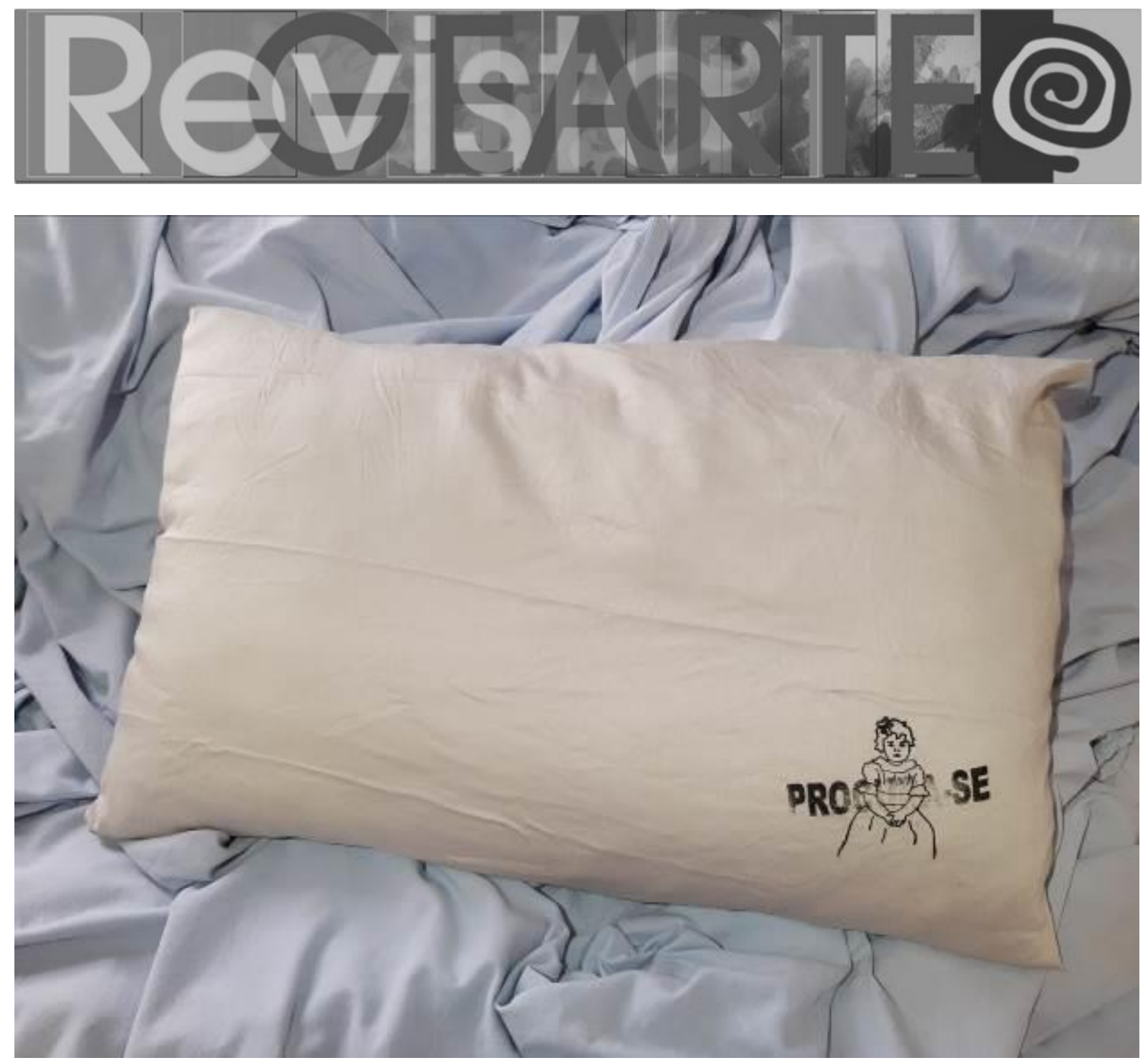

Travesseiro, 2020. 


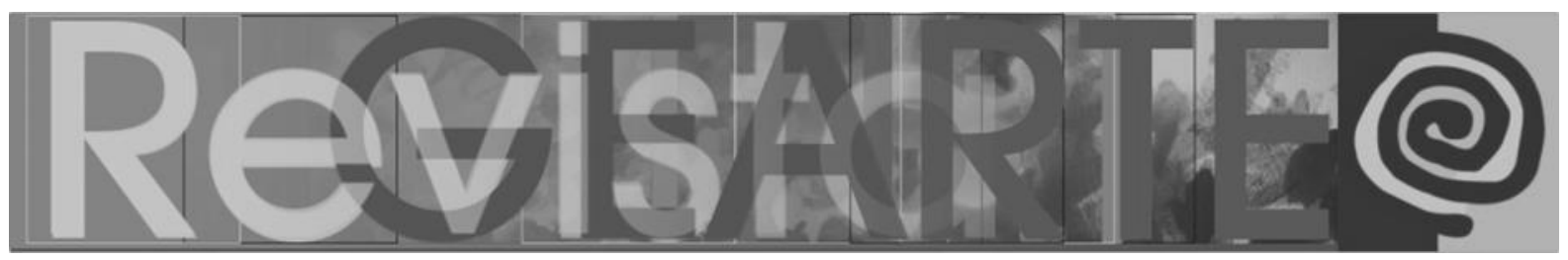

OBEDIÊNCIA:

processos de ensinar, aprender e artistar

Embora desejasse dormir até mais tarde a expectativa de conversar com a professora de minha filha impulsionou-me para fora da cama. Enquanto escovava os dentes recordei o tempo em que lidava com as ansiedades e perspectivas das famílias de meus estudantes durante as reuniões de entrega das avaliações trimestrais. Costumava preparar slides para apresentar os conteúdos, as estratégias de ação pedagógica e as competências e habilidades previstas. Também ensaiava algum discurso motivacional para atrair pais e responsáveis para a vida escolar de seus filhos e filhas. Naquela manhã de sábado, e enquanto caminhava em direção à escola de minha filha, refletia se tinha acompanhado suficientemente sua trajetória escolar. Diante da professora, escutei:

- Ela é muito obediente!

Emudeci! Não consegui acomodar a frustração, mas, preferi me manter atenta com a sensação de que algo ainda aconteceria. Imaginava escutar comentários sobre o processo de construção da escrita, sobre o desenvolvimento lógico-matemático, sobre a convivência com os demais colegas ou sobre a busca por novas experimentações com a natureza, mas, as palavras seguintes foram: "ela faz tudo direitinho", "atende aos chamados das professoras", "é querida e bemcomportada".

O incômodo me acompanhou por inúmeros dias e uma certa revolta frustração - sedimentou-se em meu corpo. Eis que imersa nas dúvidas em relação a minha atuação como professora, mãe, artista, filha, profissional (...) deparei-me com uma fotografia de minha infância e lembrei do vestidinho branco: aquele que não poderia ser manchado de barro, que não poderia ter um respingo de sorvete.

Revisitei-me na infância e vi uma estudante obediente. Revisitei-me como mãe e me percebi desejando a não obediência. Revisitei-me como professora artista e iniciei uma frente desobediente, questionando: como minhas narrativas 


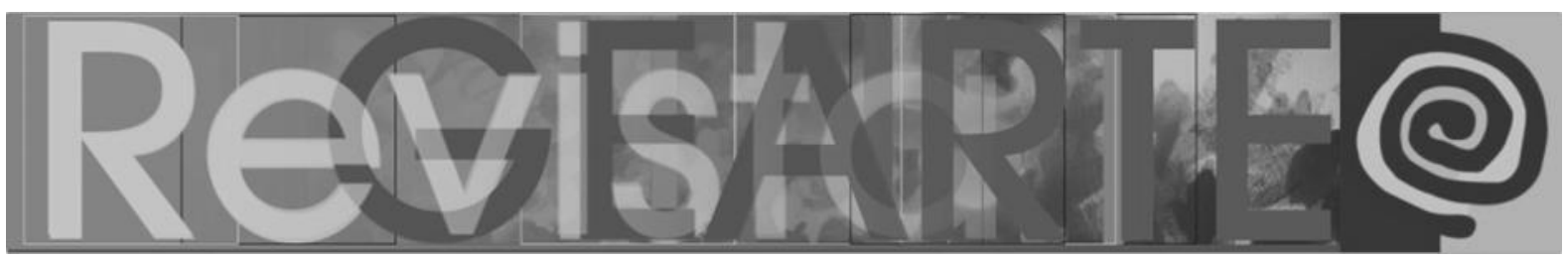

autobiográficas ecoam em processos de ensinar, aprender e artistar? Como tornarme professora inventiva diante de tantos processos artísticos e pedagógicos reguladores? Quais possíveis vulnerabilidades e riscos nos processos inventivos de ensinar? Como minhas práticas têxteis podem reverberar na formação docente? Como relacionar os incômodos subjetivos "sedimentados em meu corpo" aos processos de aprender e ensinar?

Obediência pode ser uma virtude, gera conforto. Obediência também pode se tornar alvo de cólera ou de desprezo diante de sua indignidade. Aqui, trato-a como movimento para geração de eventos. Assim, rememoro a minha história pessoal para ressignificar os sentidos de meu vestidinho branco e retorno a Pedagogia da Autonomia, de Paulo Freire, minha primeira referência como educadora, quando preconiza que "o educando mantenha vivo em si o gosto da rebeldia que, aguçando sua curiosidade e estimulando sua capacidade de arriscarse, de aventurar-se, de certa forma o 'imuniza' contra o poder apassivador do 'bancarismo'" (FREIRE, 2002, p. 27).

Obediência é uma série de vivências poéticas e narrativas inscritas nas práticas contemporâneas em arte têxtil. Parto de um relato autobiográfico e de um artefato afetivo (vestidinho branco) para ressignificar minha trajetória como professora artista. É parte da pesquisa a/r/tográfica "Narrativas Têxteis e Formação do Docente Artista" em desenvolvimento no Programa Associado de PósGraduação em Artes Visuais da Universidade Federal de Pernambuco/ Universidade Federal da Paraíba (UFPE/UFPB) e nos cursos de Graduação em Artes Visuais - Licenciatura e Bacharelado - da Universidade Federal de Pernambuco.

\section{Referência}

FREIRE, Paulo. Pedagogia da autonomia: saberes necessários à prática educativa. São Paulo: Paz e Terra, 2002. 


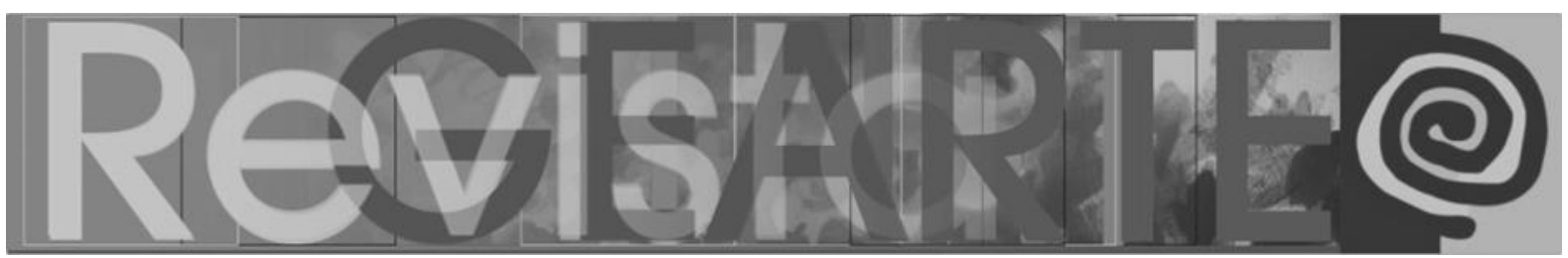

\section{Luciana Borre}

Professora e coordenadora dos Cursos de Artes Visuais - Licenciatura e Bacharelado - da Universidade Federal de Pernambuco. Professora no Programa Associado de Pós-Graduação em Artes Visuais UFPE/UFPB. Doutora em Arte e Cultura Visual pela Universidade Federal de Goiás (2014). Mestre em Educação pela PUCRS (2008); especialista em Gestão e Planejamento Escolar pela PUCRS (2006) e graduada em Pedagogia pela UFRGS (2004). Atuou como professora de Séries Iniciais e Artes Visuais na Educação Básica.

ORCID: https://orcid.org/0000-0002-1929-3734

E-mail: lucianaborre@yahoo.com.br

Currículo: http://lattes.cnpq.br/9232357001079673 